\title{
Benefit sharing for BIM implementation: Tackling the moral hazard dilemma in inter-firm cooperation
}

\author{
Linzi Zheng ${ }^{1}$, Weisheng $\mathrm{Lu}^{2}, \mathrm{Ke} \mathrm{Chen}^{3}$, Kwong Wing Chau ${ }^{4}$, and Yuhan $\mathrm{Niu}^{5}$
}

\begin{abstract}
Building information modelling (BIM) plays an important role in furthering value-creation of construction projects by advocating the inter-firm cooperation. When implementing BIM, however, individual firms inherently safeguard their self-interests regardless of the fact that inter-firm cooperation might reap joint BIM benefits for a project overall, which epitomizes a typical problem of moral hazards in project-based organizations. This paper develops an outcome-linked benefit sharing model that considers sharing joint BIM benefits among stakeholders including designers, contractors, and clients for tracking moral hazards therein. By modeling stakeholders' behaviors as evolutionary games within a principal-agent formalism, it has been deducted that (1) designers/contractors could be incentivized to cooperate had each stakeholder received a share higher than the quotient of BIM costs over value-creation in the design/construction phase; and (2) how joint BIM benefits can be more than noncooperation outcomes is key for clients to support BIM implementation.
\end{abstract}

Keywords: Building Information Modeling, Inter-firm Cooperation, Moral Hazards, Principal-Agent Theory, Evolutionary Game Model

\footnotetext{
${ }^{1}$ Postdoctoral Fellow, Corresponding author, Department of Real Estate and Construction, The University of Hong Kong, Hong Kong, Email: lizzheng@hku.hk, Telephone: +852 6626 1569;

${ }^{2}$ Associate Professor, Department of Real Estate and Construction, The University of Hong Kong, Hong Kong, Email: wilsonlu@hku.hk;

${ }^{3} \mathrm{PhD}$ candidate, Department of Real Estate and Construction, The University of Hong Kong, Hong Kong, Email: leochen@connect.hku.hk;

${ }^{4}$ Professor, Department of Real Estate and Construction, The University of Hong Kong, Hong Kong, Email: hrrbckw@hku.hk; and

${ }^{5} \mathrm{PhD}$ candidate, Department of Real Estate and Construction, The University of Hong Kong, Hong Kong, Email: yuhanniu@connect.hku.hk.
} 
Please cite this article as: "Zheng, L., Lu, W., Chen, K., Chau, K.W., and Niu, Y.H. (2017). Benefit sharing for BIM implementation: Tackling the moral hazard dilemma in inter-firm cooperation. International Journal of Project Management, 35(3), 393-405.”

\section{Introduction}

The tremendous construction demand has kindled a global interest in implementing building information modeling (BIM) in the architecture, engineering and construction (AEC) industry (Chen et al. 2015). Confronting intense competitions, sharp cost pressures, and the valuecreation demand, AEC firms find it difficult to develop so far as the project fragmentation is concerned (Ceric 2012), particularly in the Design Bid and Building (DBB) model prevailing in the industry (MacLeamy 2004). BIM offers a platform for information sharing between firms, and is recognized as able to add value to projects by enhancing management interoperability, integration, efficiency, and effectiveness (Eastman et al. 2011). As such, BIM could help move the project management from intra-firm order towards inter-firm cooperation (Eadie et al. 2013), and is described to be so advantaged that it will bring a paradigm shift to the AEC industry (Eastman et al. 2011).

Despite its virtues, BIM has not yet made a decisive step from pilot-alike or particularpurposed cases to widespread applications, wherein the euphoria around BIM is yet to be seen. It immediately begs the question of why AEC firms stand aloof from using BIM notwithstanding its advantages reported by researchers. To some extent, existing studies have addressed BIM implementation barriers such as technological factors (Redmond et al. 2012), human elements (Bryde et al. 2013), and financial influences (Son et al. 2015). Nevertheless, there leaves a sense of lacking attentions to the conflict between individual maximization and inter-firm cooperation. On the basis of economics and organization theories, firms are selfinterested individuals and behave in a way that best serves their own utilities (Hatch and Cunliffe 2013). Meanwhile, firms' activities are limited by their imperfect information, cognitive limitations and finite time, involving costly safeguarding of, and competition for, individual maximizations (Williamson 1973; Simon 1982). For implementing BIM, it engages clients and AEC firms that mainly fall into designers and contractors. Whilst clients often play 
Please cite this article as: "Zheng, L., Lu, W., Chen, K., Chau, K.W., and Niu, Y.H. (2017). Benefit sharing for BIM implementation: Tackling the moral hazard dilemma in inter-firm cooperation. International Journal of Project Management, 35(3), 393-405.”

a dominant role in promoting BIM, they actually rely on AEC firms' expertise and resources for BIM implementations - such ties are typical principal-agent (PA) relations, where bounded rational AEC firms (agencies) focusing on self-interests may well act inappropriately from the client's (the principal's) viewpoint, were their interests not aligned (Ross 1973; Postrel 2009).

Firstly, as information sharing is indispensably required, using BIM is often associated with revealing firms' proprietary information. Firms are apt to presume that by doing so would invite intensified competitions and monitoring from other firms, and cause losses to their vested benefits that are known as the proprietary cost (e.g. Berger and Hann 2007). Being required to use BIM, AEC firms thus are facing tradeoffs between BIM benefits and their proprietary costs. When BIM benefits are uncertain in comparison with present pictures of proprietary costs, decisions favoring using BIM would be very unlikely. Secondly, as one profound purport of BIM is to offer a commonly accessible information platform (Hess and Ostrom 2003), implementing BIM encounters the puzzle of 'common-pool' resources in a narrow path. In the relevant literature, given 'common-pool' resources, inefficient outcomes are frequently found, predominantly owing to individuals' free-riding and over-competition (e.g. Camerer 2003; Duffy and Ochs 2009). Given a BIM-based information platform, AEC firms are also inclined to free-riding and over-competition for obtaining possibly higher benefits than before. These firms, meanwhile, would try for safeguarding their gained benefits. Because free-riding, selfinterest safeguarding, and over-competition are all costly behaviors (Williamson 1973), in any event, firms' previous cost-benefit equilibria could become unbalanced and probably move to lower levels. Consequently, no firm would genuinely cooperate even though corporately using BIM is desired from the collective view. This epitomizes a classical problem existing in project-based organizations, as being labeled by scholars as the moral hazard dilemma, which can be prejudicial to both joint outcomes and individual utilities (Gintis 2009). 
Please cite this article as: "Zheng, L., Lu, W., Chen, K., Chau, K.W., and Niu, Y.H. (2017). Benefit sharing for BIM implementation: Tackling the moral hazard dilemma in inter-firm cooperation. International Journal of Project Management, 35(3), 393-405.”

How to tackle moral hazards in a PA relation has long been a challenging problem for scholars (Hess and Ostrom 2003; Obloj and Zemsky 2015). Researchers unanimously consent that, cooperation is intricately associated with communications, norms, and institutions. While norms and communications actually motivate firms to obey institutions (Arrighetti et al. 1997), incentives and punishments are core issues of institutional arrangements (Hess and Ostrom 2003). This paper hence resorts to incentive-alignment for encouraging inter-firm cooperation for BIM implementation. An outcome-linked benefit sharing model (OLBSM) is developed by modeling stakeholders' behaviors as evolutionary games within a principal-agent formalism. The OLBSM considers sharing joint BIM benefits among stakeholders (i.e. designers, contractors, and clients) for delivering DBB projects. Being subject to a determined environment, this study has both methodological and practical implications to other settings purposing on promoting BIM.

\section{Existing incentives of using BIM and emerging challenges}

The BIM implementation literature has sprung up over recent years. These studies are mainly geared towards inductive models for technological, organizational, or financial-based initiatives to overcome barriers to BIM adoption. Among these studies, Redmond et al. (2012) strive efforts to expand BIM applications by introducing a web service. Cao et al. (2016) propose four categories of BIM incentives from regulation, cooperation image, and revenue based upon experiences of China. Son et al. (2015), Arayici et al. (2011) and many other scholars study organizational factors such as the firms' culture that could hinder them from adopting BIM. Scholars also inspiringly argue that, as using BIM is costlier during design phases but more profitable for construction phases (Lu et al. 2014), a fee structure change for stakeholders fairly assuming BIM costs could offer proper incentives (Bryde et al. 2013). Another inspiring approach is to apply the integrated project delivery modeling (IPDM) to 
Please cite this article as: "Zheng, L., Lu, W., Chen, K., Chau, K.W., and Niu, Y.H. (2017). Benefit sharing for BIM implementation: Tackling the moral hazard dilemma in inter-firm cooperation. International Journal of Project Management, 35(3), 393-405.”

BIM-based projects (e.g. Sebastian 2011), where the key has been recognized as aligning stakeholders' incentives and goals of BIM implementation (Chang 2014).

As insightful as previous studies are, there are still deficiencies that require further exploration. Firstly, existing approaches including fee structure changes and the IPDM fail in characterizing their functions with details. Secondly, while there are scholars arguing that firms' different targets prevent them from coalition (e.g. Manu et al. 2015), they stop before going deeper into essential reasons. Thirdly, existing models for promoting BIM do not explicitly include firms' self-interests and bounded rationalities, resulting in consequences diverging from their original intentions. For instance, under cost-switching policies, a firm may increase the BIM budget only for obtaining higher profits instead of truly using it, as an increased BIM budget might be borne by other firms.

Above discussions trenchantly point out that, what is lacking is the attention to moral hazards in BIM implementation and illuminating coping strategies. What will be useful is a managerial concept that helps AEC firms overcome strong temptations to moral hazard behaviors. What is currently needed thus is a risk-free and costless method of demonstrating effects of sharing joint BIM benefits on stakeholders' behaviors when implementing BIM.

\section{Methodology and research strategy}

Methodology. This study seeks for developing an outcome-linked benefit sharing model (OLBSM) to incentivize inter-firm cooperation in the context of BIM implementation. The model development is grounded in the principal-agent (PA) theory and follows the deductive reasoning approach. The OLBSM is regarded as an ex-ante approach of sharing ex-post joint BIM benefits between clients (the principal) and designers/contractors (i.e. AEC firms, agencies). Among methods for governing PA relations, evolutionary game models have produced optimal collaboration results in laboratories (e.g. Groves and Ledyard 1977; Camerer 2003). In a similar vein, this study models BIM implementations as evolutionary games 
Please cite this article as: "Zheng, L., Lu, W., Chen, K., Chau, K.W., and Niu, Y.H. (2017). Benefit sharing for BIM implementation: Tackling the moral hazard dilemma in inter-firm cooperation. International Journal of Project Management, 35(3), 393-405.”

between stakeholders, where one stakeholder moves by considering other stakeholders' possible moves. A positive move (cooperation) is an action for a stakeholder to bear no more cost than the intrinsic production cost, which would not be the case without heading towards an aligned target. Punishment (e.g. increased costs of moves) for negative moves (noncooperation) hence is frequently paired with rewards of positive moves.

The four-step research strategy (Fig. 1). The starting point is to identify moral hazards in BIM implementation by investigating how BIM is being used and how it affects stakeholders' costs and benefits. This is done by carrying out a content analysis based on retrieved 37 scholarly papers and 19 industrial reports, where 52 real cases of BIM implementation are covered. For a coherent discourse of this study, details of the content analysis method and analytical results are given in the Appendix. The second step is to offer an explicit characterization of the value creation possibility if stakeholders all cooperate. In the third step, the relationship between sharing joint BIM benefits and stakeholders' behaviors of implementing BIM is computed. Finally, an execution procedure is suggested for applying the proposed OLBSM to BIM-based projects. 
Please cite this article as: "Zheng, L., Lu, W., Chen, K., Chau, K.W., and Niu, Y.H. (2017). Benefit sharing for BIM implementation: Tackling the moral hazard dilemma in inter-firm cooperation. International Journal of Project Management, 35(3), 393-405.”

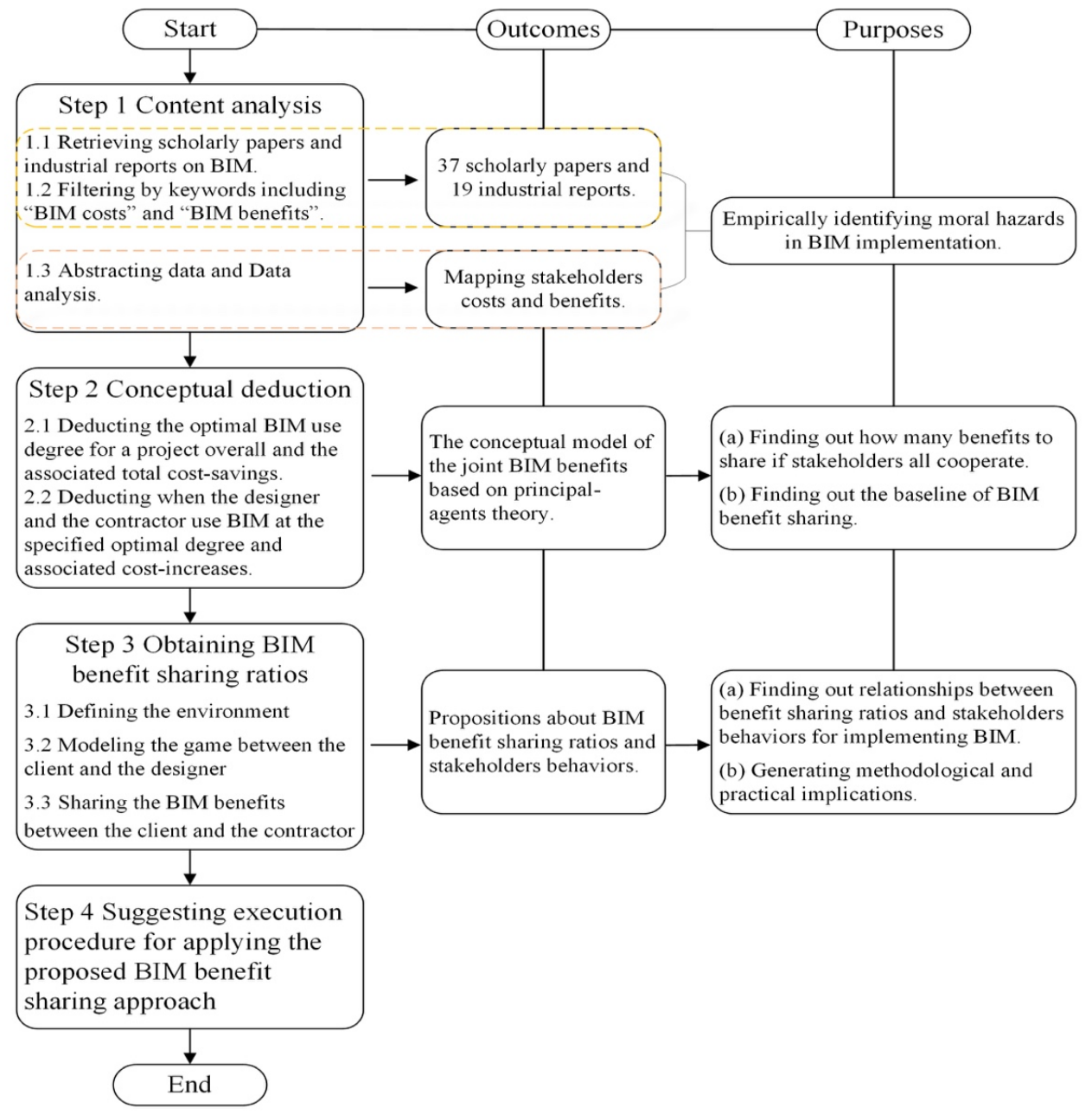

Fig. 1 The four-step research strategy

\section{Existing BIM implementation patterns}

By reviewing the retrieved 52 real cases, it is found that BIM has been being used in mainly three ways, namely, the (1) inter-firm communication (e.g. designers communicating with clients), (2) intra-firm coordination (e.g. contractors arranging construction tasks), and (3) inter-firm coordination (e.g. contractors submitting request for information (RFI) to designers). The first two ways denote particular-purposed BIM scopes, and the third way includes lifecycle BIM implementations. In the reviewed literature, lifecycle BIM implementations are much less frequently documented compared with particular-purposed BIM scopes. 
Please cite this article as: "Zheng, L., Lu, W., Chen, K., Chau, K.W., and Niu, Y.H. (2017). Benefit sharing for BIM implementation: Tackling the moral hazard dilemma in inter-firm cooperation. International Journal of Project Management, 35(3), 393-405.”

Out of reviewed 52 real cases, only 6 ones are reported as lifecycle BIM implementations, including Midfield Terminal (Abu Dhabi), Ministry of Justice (the UK), Sutter Medical Center (the US), University of Colorado Denver Research II (the US), Cathay Pacific Cargo Terminal (Hong Kong) and Vancouver Convention Center (British Columbia). The rest 46 cases emphasize BIM capabilities from particular stakeholders' perspectives. For example, in "Aquarium Hilton Garden Inn (Azhar et al. 2008)", the general contractor developed a BIM that was useful for reducing rework and organizing subcontractors. In the design phase of "Villeneuve La Garenne (McGraw Hill Construction 2010)" that was complexly structured, designers designed with BIM that helped to enhance design productivities and facilitated communications with the client and perspective tenants. Unfortunately, no further applications of BIM were reported for these projects.

The lack of lifecycle BIM implementations may be attributable to particular capabilities of BIM demanded by different projects. Yet the later discussion lends more credits to the argument that, particular-purposed BIM scopes might have been "the least costly (most beneficial)" ways of using BIM. Had they used BIM more in-depth than their individually preferred levels, AEC firms would have confronted off-balanced, or even reversed, cost-benefit relationships.

\section{Mapping costs and benefits of BIM implementation}

Facilitated by BIM, inter-firm cooperation and management activities can be enhanced such as mitigating uncertainties in schedules and budgets. On the other hand, as using BIM requires firms to manage projects collaboratively and interdependently, managerial issues become more expensive and create new costs to AEC firms compared with a traditional AEC process. Between particular-purposed BIM scopes and lifecycle BIM implementations, one distinguishing factor is the resulting costs and benefits of designers and contractors as direct 
Please cite this article as: "Zheng, L., Lu, W., Chen, K., Chau, K.W., and Niu, Y.H. (2017). Benefit sharing for BIM implementation: Tackling the moral hazard dilemma in inter-firm cooperation. International Journal of Project Management, 35(3), 393-405.”

BIM implementers. For yielding explanations to AEC firms' lethargic use of BIM, it is useful to firstly identify influences of using BIM on their benefits regarding costs it involves.

\section{Pertinent benefits and costs in the design phase}

In the design phase, it has been agreed that BIM helps improve design productivities, as it is useful for efficiently identifying and correcting design errors (Arayici et al. 2011), and saving time and staffing (e.g. Giel and Issa 2011). Using BIM, designers now can do their work more efficiently and flexibly than before (e.g. Taylor and Bernstein 2009). The quality of BIM-based designs is also agreed as more reliable than designs of 2D drawings (e.g. Arayici et al. 2011). Moreover, BIM also can expand designers' business by facilitating collaborative design and offering quality and new services to clients (e.g. Taylor and Bernstein 2009).

Meanwhile, designers have to assume new costs imposed by using BIM. To date, the commonly recognized BIM costs occurred in the design phase are technology costs of hardware, software, information infrastructure, and technical support (e.g. Becerik-Gerber and Rice 2010); and organizational costs for activities such as reviewing BIM-based decisionmakings (e.g. DPR Construction 2010). Besides, comparing with designing in traditional ways, designing with BIM costs designers much more intellectual efforts (e.g. Kaner et al. 2008), as well as involves considerable costs of labor training (e.g. Rico 2006), managing overwhelming information (e.g. Love et al. 2013) and data-checking (e.g. McGraw Hill Construction 2010).

\section{Pertinent benefits and costs in the construction phase}

In the construction phase, it is reported that BIM can facilitate diminishing reworks (e.g. Azhar et al. 2008), and produce shop drawings (e.g. Azhar 2011) and construction documents (e.g. Kaner et al. 2008). Meanwhile, contractors can update the BIM information and develop it into an 'as-built' BIM that depicts details of how a building has been built (e.g. Tang et al. 2010). An 'as-built' is useful for the construction work by extensively supporting activities such as process control (Song et al. 2012) and quality assessment (Tang et al. 2010). With BIM 
Please cite this article as: "Zheng, L., Lu, W., Chen, K., Chau, K.W., and Niu, Y.H. (2017). Benefit sharing for BIM implementation: Tackling the moral hazard dilemma in inter-firm cooperation. International Journal of Project Management, 35(3), 393-405.”

capabilities as rehearsed above, both construction productivities and building qualities can be improved (e.g. Kerosuo and Paavola 2016).

Additional costs are also incurred in the construction phase. When building with BIM, contractors often have to repurpose a BIM model for their own requirements or even reproduce it (e.g. Becerik-Gerber and Rice 2010). Moreover, although it is useful for contractors, an 'asbuilt' BIM can only be developed by enriching BIM objects with geometric and non-geometric information of building objects, which causes considerable costs to contractors for solving problems such as incompatible technologies (e.g. Bryde et al. 2013) and labor training (e.g. Becerik-Gerber and Rice 2010). Besides, as the construction phase engages many partners such as subcontractors, suppliers, and logistics, the BIM-based construction engenders significant organizational costs for contractors to coordinate their partners to work around BIM, and adapt their customary workflows to BIM-aided processes (e.g. Merschbrock and Rolfsen 2016).

\section{Imbalances of designers and contractors' costs and benefits}

While BIM benefits occurred in the design phase are appreciable, these benefits are not digested by designers solely, rather, they are concurrently enjoyed by clients and perhaps contractors. Firstly, the increased productivities attributable to designers' efforts at least practically account for clients' revenue by also saving their time and cost. Secondly, as BIMbased design offers detailed and accurate information about buildings (e.g. Arayici et al. 2011), clients could more efficiently undertake activities such as budgeting and tender-evaluating than before (e.g. Staub-French et al. 2011). Further, as a quality BIM-based design allows reworkreducing, less RFI, and many other in-depth analyses in the construction phase, designers' contributions to BIM actually provide handsome benefits to clients and contractors.

Contractors' previous cost-benefit equilibrium also could be affected by implementing BIM. While the costly development of an 'as-built' BIM is essential for enhancing construction productivities (e.g. Tang et al. 2010), at least a part of improved productivities might ultimately 
Please cite this article as: "Zheng, L., Lu, W., Chen, K., Chau, K.W., and Niu, Y.H. (2017). Benefit sharing for BIM implementation: Tackling the moral hazard dilemma in inter-firm cooperation. International Journal of Project Management, 35(3), 393-405.”

become clients' revenue depending on the contract between clients and contractors. Moreover, in general cases, any as-built drawings are delineated as clients' property (e.g. Goedert and Meadati 2008). Clients hence could obtain significant benefits from an 'as-built' BIM that is valuable for facility management (FM) and building operations (e.g. Teicholz 2013). Without a benefit sharing approach, under prevailing conditions, clients thus would derive extreme values from contractors and designers' contributions to BIM implementation considering the cost-benefit across a project lifecycle.

\section{Disequilibrium of cost-benefit translated into moral hazards}

Since BIM-imposed costs are generally borne by clients, there seems to be nothing that impedes AEC firms' extensively using BIM, even though the major BIM benefits are distributed to the client's hands. The supposed extensive BIM implementation, however, is far from true as discussed above. This paradox suggests that the moral hazard dilemma could be a vital issue existing in BIM implementation environments, which might result in a number of undesired consequences.

When the client recruits a designer, a designer who bids lower prices for producing BIM might be more competitive. After a designer who raised a low BIM budget being retained, rather than produce a quality BIM-based design, the designer might simply produce a BIM cutting the edge that is not more than a communication tool. What makes things worse is that it is often costly and time-communing for clients to examine the quality of a BIM-based design (Schade et al. 2011). For example, while a quality BIM-based design is useful for reducing rework and has sufficient constructability, these qualities perhaps can only be well proved during or even after the construction phase. Consequently, designers' inclination to not offering a quality BIM becomes higher. It has been reported that BIM has been only most often used in early periods of design phases and progressively less used in later periods (e.g. Eadie et al. 2013), which could offer side evidences to designers' adverse behaviors of using BIM. 
Please cite this article as: "Zheng, L., Lu, W., Chen, K., Chau, K.W., and Niu, Y.H. (2017). Benefit sharing for BIM implementation: Tackling the moral hazard dilemma in inter-firm cooperation. International Journal of Project Management, 35(3), 393-405.”

Subsequent to designers' possibly improper behaviors, contractors' cost-benefit would be affected when taking over the project. Under a lump-sum construction contract, with the availability of a BIM-based design, the client might expect a lower budget for the construction phase than before. Contractors immediately have chances to bear losses of decreased overhead, or even costs of reproducing a BIM model if designers' BIM turns out to be inferior. Worse still is the restriction of a DBB process that separates the construction from the design phase. Subject to a lower construction budget, it is quite possible for contractors to implement BIM in its easiest functions (e.g. visualization) and fail in developing an 'as-built' BIM. Under the cost-plus or guaranteed maximum price contracts where the budget is revisable, contractors have more incentives to claim extra BIM budget in name only, instead of truly contributing to BIM implementation and developing an 'as-built' BIM. As reported by Goedert and Meadati (2008), in many BIM-based projects, the construction information still is in terms of 2D drawings. Huber et al. (2011) also find that BIM handed over from contractors to clients frequently contains not much more than the design information. It hence is not surprising that, as valuable as it is for FM, BIM implementations are much less often documented in the FM phase than in other phases, as found by Goedert and Meadati (2008) and suggested by results of the content analysis in this paper (Table 3).

\section{The OLBSM of BIM implementation}

\section{The value-creation possibility enabled by BIM}

Assume that the BIM implementation degree is infinitely divisible, joint BIM benefits can be deducted as shown in Fig. 2. In Fig. 2, two vertical scales denoting BIM implementation degrees and associated costs, and one horizontal scale representing the process of project deliveries. For the entire project, assume the optimal BIM use degree is $B^{*}$; and for designers and contractors, let their private optimal BIM use degrees be $B_{\text {unshare }}^{i *}(i=$ designer, contractor). 
Please cite this article as: "Zheng, L., Lu, W., Chen, K., Chau, K.W., and Niu, Y.H. (2017). Benefit sharing for BIM implementation: Tackling the moral hazard dilemma in inter-firm cooperation. International Journal of Project Management, 35(3), 393-405."

The total cost of a construction project (marked as $C_{\text {total }}$ ) is $C_{\text {total }}^{B *}$ and $C_{\text {total }}^{B_{\text {unshare }}^{\text {* }}}$ when BIM is used in degrees of $B^{*}$ and $B_{\text {unshare }}^{i *}$ respectively. Designers and contractors' BIM costs are functions of their BIM use degrees (denoted as $f\left(B_{\text {unshare }}^{i *}\right)$ ). In Fig. 2, curves of $C_{\text {total }}$ and $f\left(B_{\text {unshare }}^{i *}\right)$ all diminishingly increase with the project process (the $\mathrm{x}$-axis) and the BIM implementation degree (the y-axis on the left). The three cost curves have similar shapes, which indicate that the marginal costs imposed by using BIM to designers, contractors, and the overall project could decrease after designers and contractors getting sophisticated in implementing BIM, as well as BIM benefits being scaled.

If designers and contractors both cooperate, i.e. use BIM at $B^{*}$, they will face increased costs in terms of $f\left(B^{*}\right)-f\left(B_{\text {unshare }}^{i *}\right)$. Meanwhile, when BIM is being used at $B^{*}$, the $C_{\text {total }}$ is at its minimum level $\left(C_{\text {total }}^{B *}\right)$. Had designers and contractors expanded their BIM use degrees from $B_{\text {unshare }}^{i *}$ to $B^{*}$, the $C_{\text {total }}$ could be reduced. Therefore, the difference $C_{\text {total }}^{B_{\text {unshare }}^{i *}-}$ $C_{\text {total }}^{B *}>0$ is the joint BIM benefits for an entire project, which cannot be realized if AEC firms act privately. Further, when the decrease in $C_{\text {total }}$ is higher than the sum of increases in designers and contractors' costs, i.e. $f\left(B^{*}\right)-\mathrm{f}\left(B_{\text {unshare }}^{i *}\right) \leq C_{\text {total }}^{B_{\text {unshare }}^{i *}}-C_{\text {total }}^{B *}$, by passing back shares of joint BIM benefits $\left(C_{\text {total }}^{B_{\text {unshare }}^{i *}}-C_{\text {total }}^{B *}\right)$ to cover designers/contractors' increased costs for using BIM at $B^{*}$, they could be incentivized to cooperate for implementing BIM for the sake of a project overall. 


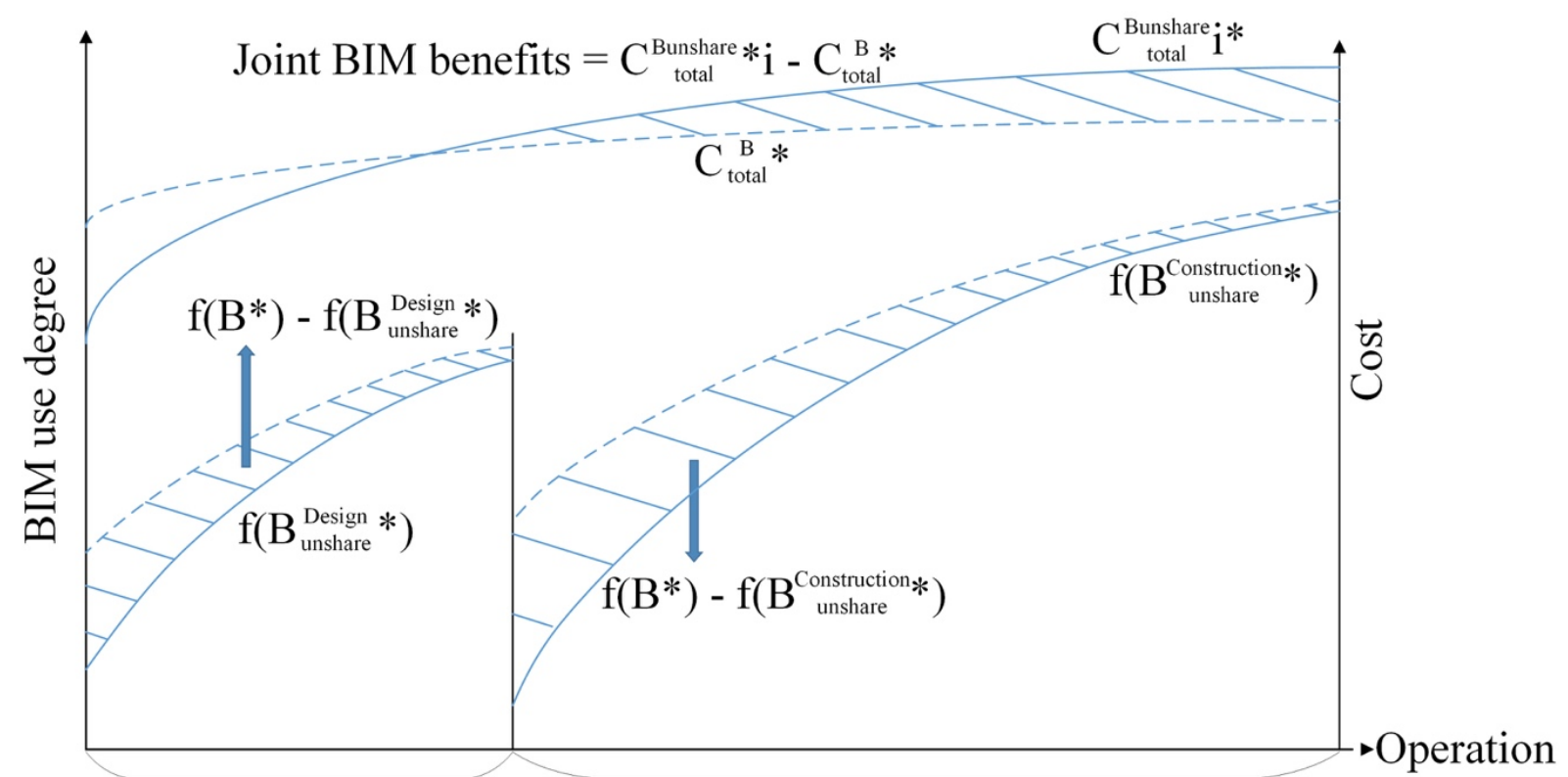

Design

Construction

Fig. 2 Joint BIM benefits derived from stakeholders' cooperation

\section{The baseline of benefit sharing}

Provided that joint BIM benefits satisfy the condition of $f\left(B^{*}\right)-\mathrm{f}\left(B_{\text {unshare }}^{\text {i* }}\right) \leq C_{\text {total }}^{B_{\text {unshare }}^{i *}}$ $C_{\text {total }}^{B *}$, it is necessary to perform the OLBSM according to a baseline that, a stakeholder who uses BIM at $B^{*}$ would receive benefits not lower than such stakeholder's vested benefits when using BIM at $B_{\text {unshare }}^{i *}$ Otherwise, the stakeholder is inclined to moral hazard behaviors or simply drops the project. This baseline hence consists of two concepts. The first concept concerns protecting agencies' (designers and contractors') interests by defining that, agencies' costs of using BIM at $B^{*}$ should be less than, or at least equal to, their costs of using BIM at their private optimal degrees $\left(B_{\text {unshare }}^{i *}\right)$. The second concept is for protecting the principal's (the client's) interest that, the principal should at least get that much benefits when agencies have used BIM at $B_{\text {unshare }}^{i *}$ Each agency hence should receive benefits derived from using BIM at $B^{*}$ in a ratio of the value added by such agency in terms of cost-savings. These two concepts can be expressed as: 
Please cite this article as: "Zheng, L., Lu, W., Chen, K., Chau, K.W., and Niu, Y.H. (2017). Benefit sharing for BIM implementation: Tackling the moral hazard dilemma in inter-firm cooperation. International Journal of Project Management, 35(3), 393-405.”

Value added by the client $=$ project value - total project budget, or

$$
V A_{\text {client }}=P_{\text {project }}-\text { Total Budget }
$$

Value added by agencies = decreases in the design/construction budget - agencies' additional BIM costs, or

$$
V A_{i}=\Delta \text { Budget }_{i}-\left[f\left(B^{*}\right)-f\left(B_{\text {unshare }}^{*}\right)_{i}\right]
$$

Therefore, each stakeholder can receive a share of joint BIM benefits as calculated by:

$$
\beta_{i}=\frac{V A_{j}}{\sum_{1}^{3} V A_{j}}, \quad(j=\text { client }, \text { designer, contractor })
$$

Following the above-specified baseline, the OLBSM could protect all stakeholders' interests in corporately using BIM by aligning their individual-maximization functions.

\section{Obtaining BIM benefit sharing ratios}

\section{Defining the BIM implementation environment}

Consider a DBB construction project, where using BIM is stipulated by contracts between clients and designers/contractors. Define the environment as two project phases, namely, the design phase and the construction phase. The client is the facility operator and to invest in BIM implementation, and owns the BIM used by the contractor at the end of the construction phase.

Suited in this environment, the client's positive strategy is carefully evaluating agencies' BIM implementations and supporting exploring BIM applications, and the negative strategy is actions on the opposite. Regarding agencies, designers' positive strategy is to offer a developed BIM-based design that elaborates detailed building descriptions and technical specifications of the project, and their negative strategy is producing a conceptual BIM-based design containing very limited information; and contractors' positive strategy is using BIM extensively and developing an 'as-built' BIM, and their negative strategy is using BIM superficially and only submitting a BIM containing not much more than the design information to the client. 
Please cite this article as: "Zheng, L., Lu, W., Chen, K., Chau, K.W., and Niu, Y.H. (2017). Benefit sharing for BIM implementation: Tackling the moral hazard dilemma in inter-firm cooperation. International Journal of Project Management, 35(3), 393-405.”

Presume that the ex-post joint BIM benefits are indefinitely divisible into the unit benefit. To convey the principal's incentives-monitoring to agencies, the ex-ante benefit sharing should be linked with agencies' actual outcomes of using BIM. Designers' share of BIM benefit hence also depends on contractors' behaviors according to a DBB process. In this regard, the game of stakeholders' BIM implementations can be separated into two parts, viz., one part between the client and the designer, and the other part between the client and the contractor.

Define joint BIM benefits as $S E=\varpi+h \xi(\xi>0 ; h>1)$, where $\varpi$ denotes the unit benefit (cost-saving) had all players acted negatively and might be a negative value. As clients' positive strategies confine and stimulate designers' positive strategies, it is reasonable to assume that the same unit benefit can be derived from either clients' or designers' positive strategy (marked as $\xi$ ). Further, let $h \xi$ denote the unit benefit derived from all stakeholders' positive strategies. Along with a DBB process, $h \xi$ cannot be observed in the design phase, so that a part of designers' share of BIM benefits has to be redeemed after the construction phase.

\section{Sharing joint BIM benefits between the client and the designer}

Along with a DBB process, it is firstly to stipulate the OLBSM between clients and designers. Being bounded rational individuals, both clients and designers have to go through learning processes in terms of trial-error-adjustments before finally finding out their optimal adaptation paths in BIM implementation environments. In terminologies of evolutionary games, a stakeholder's optimal adaptation path is termed as an evolutionary stable strategy (ESS) when participating a game. The BIM benefit sharing ratios thus can be computed by identifying stakeholders' ESSs when being engaged in BIM implementation.

The pay-off matrix for a single round of the game is given in Table 1 , where $\beta_{\text {client }}$ and $\beta_{\text {des. }}$ denote clients and designers' BIM benefit shares respectively, and $C_{\text {des. }}$ and $C_{\text {client }}^{1}$ denote designers and clients' costs of performing their positive strategies. When clients' (or 
Please cite this article as: "Zheng, L., Lu, W., Chen, K., Chau, K.W., and Niu, Y.H. (2017). Benefit sharing for BIM implementation: Tackling the moral hazard dilemma in inter-firm cooperation. International Journal of Project Management, 35(3), 393-405."

designers') positive strategy A (or C) is an ESS of the game, it can be interpreted as that, in a market consisting of numerous similar clients (or designers), a client (or a designer) who adopts the negative strategy B (or D) receive strictly lower payoffs than what adopters of strategy A (or C) would receive. Provided that when A is clients' ESS, C happens to be designers' ESS, then $(\mathrm{A}, \mathrm{C})$ is an ESS pair of the game between the designer and the client.

Table 1 The payoff matrix between the client and the designer

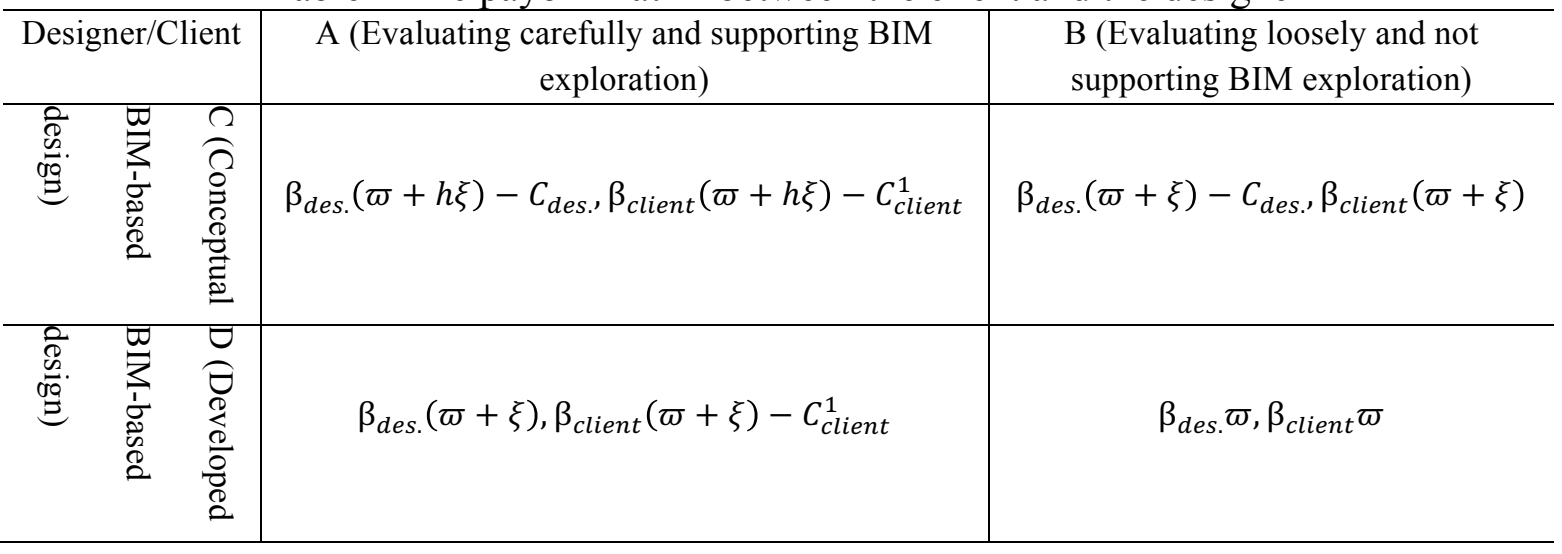

Given individual stakeholders' bounded rationalities, which strategies to adopt for single rounds of games can be assumed as following probabilistic functions. Denote $x$ (or $y$ ) as the probability for the designer (or the client) to adopt strategy $\mathrm{C}$ (or A). Any time looking up the status (s) in the design phase, the two players' next strategies have a probability function: $\mathrm{s}=\{(x, 1-x),(y, 1-y)\},(x \in[0,1], y \in[0,1])$

Let $r^{1}=(1,0)$ denote the status where either player chooses the positive strategy (A or $\mathrm{C})$ at a probability of 1 , and $r^{2}=(1,0)$ denote that either player chooses the negative strategy (B or D) at a probability of 1 . At status s, let $f^{\text {des. }}\left(r^{1}, s\right)$ be the weighted sum of probable payoffs (WSP) when the designer adopts C, and let $f^{d e s i .}\left(r^{2}, s\right)$ be the WSP when the designer adopts D. There thus exist:

$$
\begin{aligned}
& f^{\text {desi. }}\left(r^{1}, s\right)=y\left[\beta_{\text {des. }}(\varpi+h \xi)-C_{\text {des. }}\right]+(1-y)\left[\beta_{\text {des. }}(\varpi+h \xi)-C_{\text {des. }}\right] \\
& f^{\text {desi. }}\left(r^{2}, s\right)=y \beta_{\text {des. }}(\varpi+h \xi)+(1-y) \beta_{\text {des. }} \varpi
\end{aligned}
$$


Please cite this article as: "Zheng, L., Lu, W., Chen, K., Chau, K.W., and Niu, Y.H. (2017). Benefit sharing for BIM implementation: Tackling the moral hazard dilemma in inter-firm cooperation. International Journal of Project Management, 35(3), 393-405.”

The general format $\left(f^{\text {desi. }}(x, s)\right)$ of the designer's WSP hence can be represented as:

$f^{\text {desi. }}(x, s)=x f^{\text {desi. }}\left(r^{1}, s\right)+(1-x) f^{\text {desi. }}\left(r^{2}, s\right)$

Likewise, for the client, there exist:

$$
\begin{aligned}
& f^{\text {client }}\left(r^{1}, s\right)=x\left[\beta_{\text {client }}(\varpi+h \xi)-C_{\text {client }}^{1}\right]+(1-x)\left[\beta_{\text {client }}(\varpi+\xi)-C_{\text {client }}^{1}\right] \\
& f^{\text {client }}\left(r^{2}, s\right)=x\left[\beta_{\text {client }}(\varpi+\xi)\right]+(1-x) \beta_{\text {client }} \varpi \\
& f^{c l i e n t}(y, s)=y f^{c l i e n t}\left(r^{1}, s\right)+(1-y) f^{c l i e n t}\left(r^{2}, s\right)
\end{aligned}
$$

Let $\emptyset(x)=x\left[f^{\text {desi. }}\left(r^{1}, s\right)-f^{\text {desi. }}(x, s)\right]$ and $\emptyset(y)=y\left[f^{\text {client }}\left(r^{1}, s\right)-f^{\text {client }}(y, s)\right.$ be the dynamic replicator functions that respectively describe growth rates for designers and clients to approach their positive strategies (A and C), therefore,

$$
\begin{aligned}
& \emptyset(x)=x\left[f^{\text {desi. }}\left(r^{1}, s\right)-f^{\text {desi. }}(x, s)\right]=x(1-x)\left[\left(\beta_{\text {des. }} \xi-C_{\text {desi. }}\right)+y \beta_{\text {des. }} \xi(h-2)\right] \\
& \emptyset(y)=y\left[f^{\text {client }}\left(r^{1}, s\right)-f^{\text {client }}(y, s)\right]=y(1-y)\left[x \beta_{\text {client }} \xi(h-2)+\beta_{\text {client }} \xi-C_{\text {client }}^{1}\right]
\end{aligned}
$$

According to the conceptual of ESS, when $\emptyset(x)=0$ (or $\emptyset(y)=0)$, it indicates that the adopted strategy stops varying and becomes the static point for the designer (or the client). Solving Eq.11 and Eq.12 together, five static points can be computed as $E_{1}(0,0), E_{2}(0,1)$, $E_{3}(1,0), E_{4}(1,1)$, and $\left.E_{5}\left(C_{\text {client }}^{1}-\beta_{\text {client }} \xi\right) / \xi \beta_{\text {client }}(h-2),\left(\beta_{\text {des. }} \xi-C_{1}\right) / \beta_{\text {des. }} \xi(2-h)\right)$. For equilibrium analyses of the five static points, the Jacobi Matrix (Friedman 1991) is introduced as Eq. 13:

$$
\begin{aligned}
& J=\left\{\begin{array}{cc}
\frac{d \Phi(x)}{d x} & \frac{d \phi(x)}{d y} \\
\frac{d \Phi(y)}{d x} & \frac{d \emptyset(y)}{d y}
\end{array}\right\} \\
& =\left\{\begin{array}{cc}
(1-2 x)\left[\left(\beta_{\text {des. }} \xi-C_{1}\right)+y \beta_{\text {des. }} \xi(h-2)\right], & x(1-x) \beta_{\text {des. }} \xi(h-2) \\
y(1-y) \beta_{\text {client }} \xi(h-2), & (1-2 y)\left[x \beta_{\text {client }} \xi(h-2)+\beta_{\text {client }} \xi-C_{\text {client }}^{1}\right]
\end{array}\right\}
\end{aligned}
$$

The determinant of the Jacobi Matrix $(\operatorname{det} J)$ and the matrix trace $(\operatorname{tr} J)$ are:

$$
\begin{aligned}
& \text { det } J=(1-2 x)(1-2 y)\left[\left(\beta_{\text {des. }} \xi-C_{\text {desi. }}\right)+y \beta_{\text {des. }} \xi(h-2)\right]\left[x \beta_{\text {client }} \xi(2-h)-C_{\text {client }}^{1}-\right. \\
& \left.\beta_{\text {client }} \xi\right]+x y \beta_{\text {des. }} \beta_{\text {client }}(1-x)(1-y) \xi^{2}(h-2)^{2}
\end{aligned}
$$


Please cite this article as: "Zheng, L., Lu, W., Chen, K., Chau, K.W., and Niu, Y.H. (2017). Benefit sharing for BIM implementation: Tackling the moral hazard dilemma in inter-firm cooperation. International Journal of Project Management, 35(3), 393-405.”

$\operatorname{tr} J=(1-2 x)\left[\left(\beta_{\text {des. }} \xi-C_{\text {desi. }}\right)+y \beta_{\text {des. }} \xi(h-2)\right]+(1-2 y)\left[x \beta_{\text {client }} \xi(2-h)-\beta_{\text {client }} \xi-\right.$

$\left.C_{\text {client }}^{1}\right]$

Replace static points from $E_{1}$ to $E_{5}$ to Eq.14 and Eq.15 (Table 2). If a $E_{i}(i=1 \sim 5)$ simultaneously satisfies $\operatorname{det} J>0$ and $\operatorname{tr} J<0$, then $E_{i}$ is an optimal pair of both players' ESSs in the game.

Table 2 Partial stationary analyses of five equilibrium points

\begin{tabular}{c|c|c}
\hline Static points & Jacobi matrix determinants & Matrix trace \\
\hline$E_{1}(0,0)$ & $\left(\beta_{\text {des. }} \xi-C_{\text {desi. }}\right)\left(\beta_{\text {client }} \xi-C_{\text {client }}^{1}\right)$ & $\xi-C_{\text {desi. }}-C_{\text {client }}^{1}$ \\
$E_{2}(0,1)$ & {$\left[\beta_{\text {des. }} \xi(h-1)-C_{\text {desi. }}\right]\left[C_{\text {client }}^{1}-\left(\beta_{\text {client }} \xi\right]\right.$} & $C_{\text {client }}^{1}-C_{\text {desi. }}+\xi\left(\beta_{\text {des. }} h-1\right)$ \\
$E_{3}(1,0)$ & $\left(C_{\text {desi. }}-\beta_{\text {des. }} \xi\right)\left[\beta_{\text {client }} \xi(h-1)-C_{\text {client }}^{1}\right.$ & $C_{\text {desi. }}-C_{\text {client }}^{1}+\xi\left[\beta_{\text {client }} h-1\right]$ \\
$E_{4}(1,1)$ & {$\left[\beta_{\text {des. }} \xi(h-1)-C_{\text {desi. }}\right]\left[\beta_{\text {client }} \xi(h-1)-C_{\text {client }}^{1}\right]$} & $C_{\text {desi. }}+C_{\text {client }}^{1}-\xi(h-1)$ \\
$E_{5}(x, y)$ & $-x y(1-x) \beta_{\text {des. }} \xi(h-1)(1-y) \beta_{\text {client }} \xi(h-2)$ & 0 \\
\hline
\end{tabular}

\section{Equilibrium analysis of benefit sharing in the design phase}

When $\xi=\frac{C_{\text {desi. }}}{\beta_{\text {des. }}}$ or $\frac{C_{\text {client }}^{1}}{\beta_{\text {client }}}$, the Jacobi Matrix determinants equal zero. A conditional analysis on values of $\xi, \frac{C_{\text {desi. }}}{\beta_{\text {des. }}}$, and $\frac{C_{\text {client }}^{1}}{\beta_{\text {client }}}$ hence is the same way of identifying which pairs of strategies are ESS pairs of the game between the client and the designer.

Proposition I: If $1<h<2$, the sufficient condition for designers to cooperate is $\beta_{\text {des. }}>\frac{C_{\text {desi. }}}{\xi}$.

Proof: when $\frac{C_{\text {desi. }}}{\xi}<\beta_{\text {des. }}<\frac{C_{\text {desi. }} \beta_{\text {client }}}{C_{\text {client }}^{1}}$, or $\beta_{\text {des. }}>\frac{C_{\text {desi. }} \beta_{\text {client }}}{C_{\text {client }}^{1}}>\frac{1}{\xi}$ and $1<h<\frac{C_{\text {client }}^{1}-C_{\text {desi. }}}{\beta_{\text {client }} \xi}$, $E_{3}(1,0)$ is the ESS; when $\frac{\beta_{\text {des. }}}{C_{\text {desi. }}}>\frac{\beta_{\text {client }}}{C_{\text {client }}^{1}}>\frac{1}{\xi}$ and $\frac{C_{\text {client }}^{1}+C_{\text {desi. }}}{\xi}+1<h<2, E_{4}(1,1)$ is the ESS; and $\frac{C_{d e s i .}}{\xi}>\frac{1}{\xi}$

The scenario of $1<h<2$ describes a situation in which joint BIM benefits are rather mild even though stakeholders all adopt positive strategies. Under this condition, if designers' 
Please cite this article as: "Zheng, L., Lu, W., Chen, K., Chau, K.W., and Niu, Y.H. (2017). Benefit sharing for BIM implementation: Tackling the moral hazard dilemma in inter-firm cooperation. International Journal of Project Management, 35(3), 393-405.”

share is higher than $\frac{C_{\text {desi. }}}{\xi}$, they would contribute to BIM implementation. Only when $\frac{\beta_{\text {client }}}{C_{\text {client }}^{1}}>$ $\frac{1}{\xi}$ and $\frac{C_{\text {client }}^{1}+C_{\text {desi. }}}{\xi}+1<h<2$, the client is to support BIM implementation positively.

Proposition II: If $2<h<\frac{C_{\text {client }}^{1}}{\beta_{\text {client }} \xi}+1$, the sufficient condition for designers to cooperate is $\beta_{\text {des. }}>\frac{C_{\text {desi. }}}{\xi}$

Proof: When $\frac{C_{\text {desi. }}}{\xi}<\beta_{\text {des. }}<\frac{C_{\text {desi }} \beta_{\text {client }}}{C_{\text {client }}^{1}}$, if $2<h<\frac{C_{\text {client }}^{1}}{\beta_{\text {client }} \xi}+1, E_{3}(1,0)$ is the ESS; when $\beta_{\text {des. }}>\frac{C_{\text {desi. }} \beta_{\text {client }}}{C_{\text {client }}^{1}}>\frac{1}{\xi}, E_{4}(1,1)$ is the ESS; and $\frac{C_{\text {desi. }}}{\xi}>\frac{1}{\xi}$.

Proposition III: If $h>\frac{C_{\text {client }}^{1}}{\beta_{\text {client }} \xi}+1>2$, the sufficient condition for both designers and clients to cooperate is $\beta_{\text {des. }}>\frac{C_{\text {desi. }}}{\xi}$.

Proof: When $\frac{C_{\text {desi. }}}{\xi}<\beta_{\text {des. }}<\frac{C_{\text {desi. }} \beta_{\text {client }}}{C_{\text {client }}^{1}}$, if $h>\frac{C_{\text {client }}^{1}}{\beta_{\text {client }} \xi}+1>2, E_{4}(1,1)$ is the ESS; when $\beta_{\text {des. }}>\frac{C_{\text {desi. }} \beta_{\text {client }}}{C_{\text {client }}^{1}}>\frac{1}{\xi}, E_{4}(1,1)$ is the ESS; and $\frac{C_{\text {desi. }}}{\xi}>\frac{1}{\xi}$.

Propositions II and III describe situations in which joint BIM benefits are significant if stakeholders all cooperate. In this case, as long as $\beta_{\text {des. }}>\frac{C_{\text {desi. }}}{\xi}$, designers and clients' utility functions could be successfully aligned. When $h$ is even higher than $\frac{C_{c l i e n t}^{1}}{\beta_{\text {client } \xi}}+1$, the ESS is converging to $E_{4}(1,1)$, suggesting both the designer and the client would adopt positive strategies when implementing BIM.

A more general analysis could be done by analyzing the scenario of $h=2$. Assume $C_{\text {client }}^{1}>C_{\text {desi. }}$, and replace $h=2$ into Eq.14 and Eq.15, then $E_{5}\left(\frac{\beta_{\text {client }} \xi-C_{\text {client }}^{1}}{\xi \beta_{\text {client }}(2-h)}, \frac{\beta_{\text {des. }} \xi-C_{\text {desi. }}}{\beta_{\text {des. }} \xi(2-h)}\right)$ would be the saddle point of the game. In Fig. 3, the ESS pair depends on the saddle point 
Please cite this article as: "Zheng, L., Lu, W., Chen, K., Chau, K.W., and Niu, Y.H. (2017). Benefit sharing for BIM implementation: Tackling the moral hazard dilemma in inter-firm cooperation. International Journal of Project Management, 35(3), 393-405.”

$E_{5}\left(\frac{\beta_{\text {client }} \xi-C_{\text {client }}^{1}}{\xi \beta_{\text {client }}(2-h)}, \frac{\beta_{\text {des }} \xi-C_{\text {desi }}}{\beta_{\text {des. }} \xi(2-h)}\right)$. If $E_{5}$ originally lands in zone I, the competing system is more probable to converge to $E_{4}$ after trail-error adjustments.

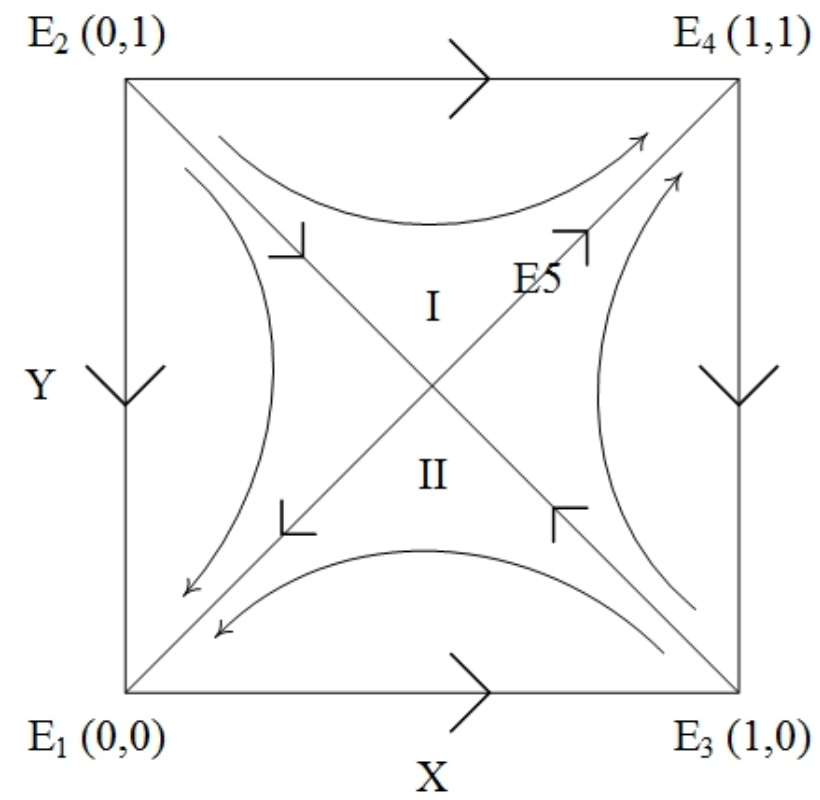

Fig. 3 The adaptive evolution of the game when $h \geq 2$

\section{Sharing joint BIM benefits between the client and the contractor}

In the construction phase, it is to share the remaining joint BIM benefits between the client and the contractor for delivering a BIM-based project. By analogizing the game between the client and the designer, it can be deducted that the sufficient condition for the contractor to cooperate is $\beta_{\text {con. }}>\frac{C_{\text {con. }}}{\mu}$ subject to the different values of $h$, where $\mu$ is the additional unit benefit (costsavings) derived from either the client or the contractor's positive strategy. For enlightening how a benefit sharing policy governs BIM implementation in the construction phase, $\beta_{\text {con }}$ is deducted in an alternative way by following a standard PA model of Hölmstrom and Milgrom's (Hölmstrom and Milgrom 1991).

Denote the contractor's actions of using BIM as $a(a \in A)$, where $A$ is a onedimensional vector. Outcomes of contractors' BIM implementation can be written as $\mathrm{y}_{\text {con. }}=$ $a+\varphi$. Let $W\left(y_{\text {con. }}\right)=s+\beta_{\text {con.* }} y_{\text {con. }}(\mathrm{s}>0)$ be incentives from clients to contractors that 
Please cite this article as: "Zheng, L., Lu, W., Chen, K., Chau, K.W., and Niu, Y.H. (2017). Benefit sharing for BIM implementation: Tackling the moral hazard dilemma in inter-firm cooperation. International Journal of Project Management, 35(3), 393-405."

depends on observable $\mathrm{y}_{\text {con. }}$. Prevailing in the project governance literature, the risk averse contractor is a working assumption (e.g. Ward and Chapman 1994). Also because BIM is relatively new to contractors, the risk averse and bounded rational contractor may well be sensitive to BIM costs. As a result, contractors' perceived BIM costs $P C_{c o n}$. $(a)$ is very likely to be higher than what $f_{\text {con. }}(a)$ actually is. It is thus reasonable to assume $P C_{c o n}(a)=\frac{\mathrm{k} a^{2}}{2}$ $(k>0)$, where a higher value of $k$ denotes more serious adverse effects of BIM costs on contractors. In addition, joint BIM benefits allocated to the contractor can be written as:

$$
\pi_{\text {con. }}=W-P C_{\text {con. }}(a)=s+\beta_{\text {con. }}(a+\varphi)-\frac{\mathrm{k} a^{2}}{2}
$$

Let $R$ denote contractors' random benefits derived from BIM implementation that follow the normal distribution function. Let $r(r>0)$ be contractors' risk averse degree, for simplicity, $R$ can be represented by $\frac{r \beta_{c o n}{ }^{2} \sigma^{2}}{2}$, where $\sigma^{2}$ is the variance that measures how far a series of random BIM benefits spread out from their mean value. Further, the certainty equivalence of contractors' BIM benefits can be written as:

$$
C E\left(\pi_{\text {con. }}\right)=\left(E\left(\pi_{\text {con. }}\right)-R\right)=s+\beta_{\text {con. }} a-\frac{k a^{2}}{2}-\frac{r \beta_{c o n .}{ }^{2} \sigma^{2}}{2}
$$

Let $\pi_{0}$ be contractors' benefits if they use BIM at $B_{\text {unshare }}^{i *}$. According to the benefit sharing baseline (Eq.3), if $C E\left(\pi_{\text {con. }}\right)$ is lower than $\pi_{0}$, contractors are inclined to private actions instead of cooperation. Therefore, joint BIM benefits allocated to contractors are constrained by $C E\left(\pi_{c o n}\right) \geq \pi_{0}$. As contractors act for individual-maximization and there exists $\operatorname{Max}\left(\pi_{0}\right) \vDash \operatorname{Max}\left(C E\left(\pi_{c o n}\right)\right)$, the consistent condition of incentives from the client to the contractor can be computed as $a^{*}=\frac{\beta_{c o n}}{k}$. Meanwhile, the client also acts for individualmaximization, and thus a simultaneous equations system exists in terms of: 
Please cite this article as: "Zheng, L., Lu, W., Chen, K., Chau, K.W., and Niu, Y.H. (2017). Benefit sharing for BIM implementation: Tackling the moral hazard dilemma in inter-firm cooperation. International Journal of Project Management, 35(3), 393-405.”

$$
\left\{\begin{array}{c}
\operatorname{Max} .\left(\mathrm{y}_{\text {client }}\right)=\operatorname{Max} .\left(\mathrm{y}_{\text {con. }}-\mathrm{W}\left(\mathrm{y}_{\text {con. }}\right)\right) \\
\text { s.t. }\left(\mathrm{s}+\beta_{\text {con. }} a\right)-\frac{\mathrm{k} a^{2}}{2}-\frac{r \beta_{\text {con. }}{ }^{2} \sigma^{2}}{2} \geq \pi_{0} \\
a^{*}=\frac{\beta_{\text {con. }}}{k}
\end{array}\right.
$$

By solving Eqs.18, the optimal incentive coefficient from the client to the contractor, i.e. contractors' BIM benefit sharing ratio, is computed as:

$$
\beta_{\text {con. }}^{*}=\frac{1}{1+r k \sigma^{2}}
$$

\section{Implications of the OLBSM}

The developed OLBSM has significant implications for analyzing incentive mechanisms of stimulating AEC firms' cooperation in BIM implementation. The designer and the contractor could be incentivized to cooperate if each of them receives a share of joint BIM benefits not lower than the quotient of such stakeholder's BIM costs over value-creation in the associated project phase. The equilibrium analysis of the game between clients and designers also shows that clients' attitudes towards BIM implementation are subject to the value of $h$, which captures how joint BIM benefits could be more than noncooperation outcomes. As implied by Proposition I, when joint BIM benefits are not eminent $(1<h<2)$, the client would not positively support BIM implementation or even not be willing to adopt BIM at all. Comparatively, designers perhaps are more inclined to cooperatively using BIM were they adequately incentivized, even if implementing BIM is not sufficiently profitable from the client's perspective.

Moreover, our model indicates that how contractors' cooperation can be incentivized significantly affects both designers and clients' behaviors associated with BIM implementation, as well as plays a crucial role in reaping joint BIM benefits. As shown in Fig. 3, when $h$ becomes larger, both the abscissa axis and the longitudinal coordinate of $E_{5}$ become smaller, and zone I expends, suggesting that both the client and the designer are more inclined to 
Please cite this article as: "Zheng, L., Lu, W., Chen, K., Chau, K.W., and Niu, Y.H. (2017). Benefit sharing for BIM implementation: Tackling the moral hazard dilemma in inter-firm cooperation. International Journal of Project Management, 35(3), 393-405.”

adopting positive strategies when implementing BIM, ceteris paribus. On the other hand, given determined technological capabilities of BIM, the value of $h$ is a function of contractors' BIM implementation outcomes. Therefore, it is imperative to maximize $h$ in the construction phase, i.e., incentivize contractors to implement BIM at $B^{*}$. Aligning Eq.18 and Eq.19, it can be computed that $a^{*}=\frac{1}{k\left(1+r k \sigma^{2}\right)}$, which represents contractors' optimal BIM use degree subject to clients' incentives. Provided that the incentive-alignment between the client and the contractor is well devised, $a^{*}$ should be equal to $B^{*}$, which further depends on contractors' risk averse degree, their cognitive knowledge of BIM costs, as well as variances in their randomly received BIM benefits.

\section{Execution procedure for applying the OLBSM}

The execution procedure for applying the OLBSM to BIM-based construction projects is suggested as consisting of five steps (Fig. 4). The first step is to identify $B^{*}$ and joint BIM benefits therein, because it is worth sharing joint BIM benefits if, and only if $f\left(B^{*}\right)-$ $f\left(B_{\text {unshare }}^{i *}\right) \leq C_{\text {total }}^{B_{\text {unshare }}^{i *}}-C_{\text {total }}^{B *}$. Since the OLBSM has to be stipulated ex-ante, the forecast of $B^{*}$ could be depending on traits of a project in plan (e.g. building structure) and extant BIM capabilities.

The second step is for clients to choose an optimal approach to implement $B^{*}$ among options such as hiring a BIM consultant and sharing joint BIM benefits with designers and contractors. Once a benefit sharing approach is adopted, it is necessary to make $B^{*}$ well acknowledged by all stakeholders. The third step is to study costs and benefits governing designers and contractors' BIM implementation policies, and the information of their $B_{\text {unshare }}^{i *}$ as accurately as possible before engaging them into the OLBSM. In this step, attentions have to be attached to the fact that, BIM costs could include monetary costs (items can be monetized directly such as software, hardware, and labor training) and organizational costs (items that can 
Please cite this article as: "Zheng, L., Lu, W., Chen, K., Chau, K.W., and Niu, Y.H. (2017). Benefit sharing for BIM implementation: Tackling the moral hazard dilemma in inter-firm cooperation. International Journal of Project Management, 35(3), 393-405.”

only be indirectly monetized such as coordination costs, workflow changes and administrations) regarding how these two types of costs occur (e.g. one-time or continuously).

On identifying BIM costs of each stakeholder, the fourth step is to obtain the BIM benefit sharing ratios subject to $\left\{\begin{array}{c}\beta_{i}=\frac{V A_{j}}{\sum_{1}^{3} V A_{j}} \\ \beta_{\text {des. }}>\frac{C_{\text {desi. }}}{\xi} \text {. Note that the calculation of } \xi \text { and } h \xi \text { should } \\ \beta_{\text {con. }}{ }^{*}=\frac{1}{1+r k \sigma^{2}}\end{array}\right.$ consider the present value add by using BIM to the FM phase when stipulating the benefits sharing between the client and the designer/contractor. The fifth step is for clients to communicate the OLBSM with designers and contractors, and stipulate it in both design and construction contracts. This step is necessary to build confidences in designers and contractors for taking up cooperative behaviors, i.e. implementing BIM at $B^{*}$. Adequate communications about the OLBSM is also helpful to perform the clause that, if $B^{*}$ turns out not having been achieved at the end of contracts, designers and contractors will not receive any shares of joint BIM benefits other than predetermined minimum payments from clients.

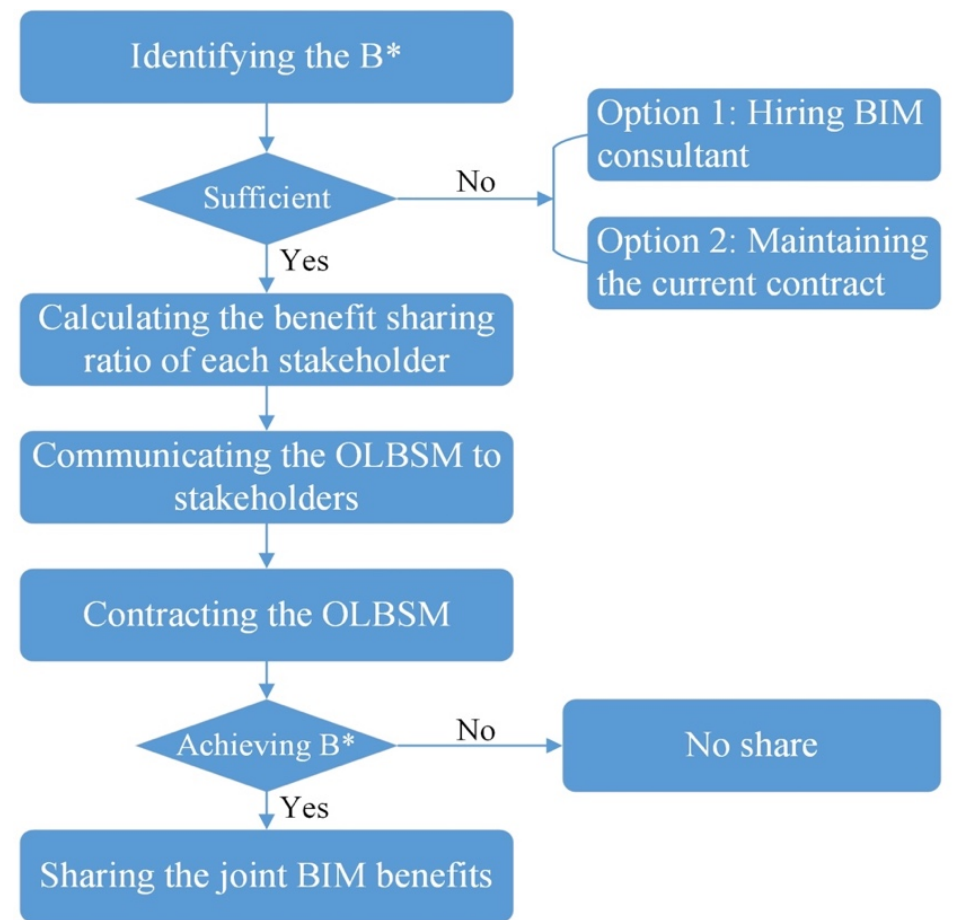

Fig. 4 The execution procedure of the proposed OLBSM 
Please cite this article as: "Zheng, L., Lu, W., Chen, K., Chau, K.W., and Niu, Y.H. (2017). Benefit sharing for BIM implementation: Tackling the moral hazard dilemma in inter-firm cooperation. International Journal of Project Management, 35(3), 393-405.”

\section{Concluding remarks}

Rather than its technology piecemeal that improves particular management activities only, BIM is also under the scrutiny of professionals emphasizing it as a lifecycle process requiring interfirm cooperation (Succar 2010; Eastman et al. 2011). As such, challenges of better promoting BIM are emerging to both the industry and the academia, giving rise to attentions to issues not previously addressed — subject to moral hazards under the asymmetric information, it is simply impossible for the client to achieve expected joint BIM benefits unless launching a proper incentive-alignment mechanism.

Trading off traditional project management systems against BIM implementation, AEC firms are expecting that their individual utilities can be increased. Constrained by their bounded rationalities, designers and contractors focusing on self-interests extend no more than their private BIM use degrees that are perceived to be the most beneficial, unless the associated costbenefit is counterbalanced at a new level. In this paper, an outcome-linked benefit sharing model (OLBSM) has been developed to incentivize inter-firm cooperation in the context of BIM implementation. In the OLBSM, the optimization problem is solved for reaping costsavings for a project overall, and the benefit sharing problem is addressed according to the value added by each stakeholder. After sharing joint BIM benefits among clients, designers, and contractors in this way, no stakeholder after cooperation has to bear a loss, and thereby is motivated to implement BIM more extensively. If properly performed, the OLBSM could help the AEC industry develop towards inter-firm cooperation, and thereby realize synergistic value-creation of construction projects.

As innovative as it is, the OLBSM still has several problematic aspects. Firstly, the modeling process is suited in a classic PA formalism, where the asymmetric information between the principal and agencies is customarily taken. Nevertheless, as it can alleviate the degree of asymmetric information between stakeholders, implementing BIM may well lower 
Please cite this article as: "Zheng, L., Lu, W., Chen, K., Chau, K.W., and Niu, Y.H. (2017). Benefit sharing for BIM implementation: Tackling the moral hazard dilemma in inter-firm cooperation. International Journal of Project Management, 35(3), 393-405.”

costs of monitoring agencies' behaviors (Hölmstrom 1979). Under this condition, it is possible that behavior-based benefit sharing methods are more appropriate to offer incentives than outcome-linked approaches (Eisenhardt 1989). Secondly, the payment schemes from clients to designers/contractors have not been sufficiently discussed, which, however, might influent the determination of benefit sharing ratios. For example, designers could charge clients either by approved design quantities (DQ) or by design duration (DD). Under DQ contracts, designers might be exposed to higher risks of assuming additional BIM costs, while DD contracts might leave clients being exposed to higher risks. Thirdly, the above two points further lead to another problem that, heterogeneities among different clients, designers, contractors, and projects also might affect how to devise optimal benefit sharing approaches.

Indeed, for designing a proper BIM benefit sharing mechanism, it needs to consider manifold factors than what have been discussed in the present study, including calculations of each stakeholder's BIM costs and benefits, the applicability of a particular benefit sharing approach, and influences of bi-directional negotiations. The successful design and execution of an OLBSM, together with the legitimacy and acceptance of more extensive BIM implementations, depend on clear BIM objectives, procedural equities, and inclusive processes, as well as engage rigorous analysis of different incentive-alignment options to assess their possible effects on both beneficiaries and efforts. In order to ultimately mitigate moral hazards and incentivize inter-firm cooperation in BIM implementation, these issues all require further explorations.

\section{Acknowledgement}

This study is jointly supported by the General Research Fund (Project No. 17205614) of the Hong Kong Research Grant Council (RGC) and HKU Seed Funding Programme for Basic Research (Project No. 201511159296). 
Please cite this article as: "Zheng, L., Lu, W., Chen, K., Chau, K.W., and Niu, Y.H. (2017). Benefit sharing for BIM implementation: Tackling the moral hazard dilemma in inter-firm cooperation. International Journal of Project Management, 35(3), 393-405.”

\section{Appendix}

\section{The content analysis method}

The sample. A three-stage strategy was adopted for locating comprehensive articles about BIM benefits and costs. Firstly, the English language literature in the "Google Scholar" database was screened by searching "BIM benefits" and "BIM cost" headings for the period between 2004 and 2016. 584 and 203 scholarly articles were located respectively. Secondly, the retrieved literature was skimmed through for contents on BIM costs and benefits. After filtering, there remained 37 eligible scholarly articles, consisting of 26 journal papers, 8 conference papers, and 3 dissertations. Thirdly, the mainstream industry analytics reports have been searched, and 19 reports about BIM implementation were retrieved. In total, this search yielded 56 articles, covering 52 real cases of BIM implementations, which could offer a fairly comprehensive sample for the content analysis in the present study.

Coding Scheme. Retrieved articles are divided into case-based and survey/model-based articles according to their methods. Each real case was counted as one vote to a documented BIM cost/benefit item, and an article without real cases was counted as one vote to per documented item. The sampled articles were sorted according to various casual elements of cost/benefit items and different project phases in which these items have been recognized. After a preliminary sorting, authors then categorized benefit items into Communication, Productivity, Competitiveness, and Coordination; and categorized cost items into Technologies, Labor training, Data-checking and Organization costs. When sorting BIM cost/benefit items, numbers of votes that each cost/benefit item gained also were marked. The abstracted data was further organized by BIM cost/benefit items, their causal elements and gained votes, as project phases where they were recognized by the literature (i.e. the design phase, the construction phase, and the FM phase).

\section{Results of the content analysis}


Table 3 BIM benefits in different project phases

BIM benefits in the design phase

\begin{tabular}{|c|c|c|}
\hline Benefit & Causal items & Votes \\
\hline \multirow[t]{10}{*}{ Design productivity } & Design assessments (e.g. energy used) & 26 \\
\hline & Higher design quality & 15 \\
\hline & Efficient clash detection & 15 \\
\hline & Cooperative design & 11 \\
\hline & Efficient design changes & 8 \\
\hline & Facilitating conceptual design & 6 \\
\hline & Design flexibility & 5 \\
\hline & Time saving & 3 \\
\hline & Minimizing design staffing & 2 \\
\hline & BIM design reuse & 2 \\
\hline \multirow[t]{3}{*}{ Communication } & Better communicating the design intent & 17 \\
\hline & Visualization & 16 \\
\hline & Information sharing & 4 \\
\hline \multirow{3}{*}{$\begin{array}{l}\text { Keep pace with market } \\
\text { competition }\end{array}$} & Design bidding support & 1 \\
\hline & Providing new design services & 1 \\
\hline & Maintaining working relations with the client & 1 \\
\hline \multicolumn{3}{|c|}{ BIM benefits in the construction phase } \\
\hline Benefit & Causal items & Votes \\
\hline \multirow{11}{*}{$\begin{array}{l}\text { Construction conduction } \\
\text { support }\end{array}$} & Reduced change orders & 17 \\
\hline & On budget and cost saving & 11 \\
\hline & Improved shop drawings & 9 \\
\hline & Safety management & 8 \\
\hline & Improved construction quality & 8 \\
\hline & Work sequencing improved & 7 \\
\hline & Efficient documentation & 7 \\
\hline & Material supply management & 4 \\
\hline & Environment management & 4 \\
\hline & Installation support/instruction & 3 \\
\hline & Rework reduced & 3 \\
\hline \multirow[t]{4}{*}{ Preconstruction support } & Construction planning and constructability assessment & 29 \\
\hline & Facilitating scheduling & 19 \\
\hline & Clash detection & 12 \\
\hline & Spatial coordination & 6 \\
\hline \multirow[t]{2}{*}{ Stakeholder coordination } & Improved coordination with other stakeholders & 20 \\
\hline & Reduced RFI & 12 \\
\hline \multirow{2}{*}{$\begin{array}{l}\text { Keep pace with market } \\
\text { competition }\end{array}$} & Efficient construction tendering & 8 \\
\hline & Maintaining working relations with the client & 5 \\
\hline \multicolumn{3}{|c|}{ BIM benefits in the operation and maintenance phase } \\
\hline Benefit & Causal items & Votes \\
\hline \multirow[t]{2}{*}{ Facility management } & Facility management and maintenance & 7 \\
\hline & Facility management tendering & 1 \\
\hline
\end{tabular}


Please cite this article as: "Zheng, L., Lu, W., Chen, K., Chau, K.W., and Niu, Y.H. (2017). Benefit sharing for BIM implementation: Tackling the moral hazard dilemma in inter-firm cooperation. International Journal of Project Management, 35(3), 393-405."

Table 4 BIM-imposed costs in different project phases

\begin{tabular}{|l|l|l|c|}
\hline \multicolumn{2}{|c|}{ Design Phase } & \multicolumn{2}{c|}{ Construction Phase } \\
\hline Cost item & Votes & Cost item & Votes \\
\hline Technologies & 24 & Technologies & 22 \\
\hline Labor training & 12 & Additional coordination & 13 \\
\hline Additional coordination & 10 & Labor training & 12 \\
\hline Ensuring the data accuracy & 6 & BIM-based decision review & 8 \\
\hline BIM-based decision review & 9 & Organization cost & 8 \\
\hline Adding more design details & 4 & Repurposing BIM design & 7 \\
\hline Early decision-making & 3 & Developing as-built BIM & 6 \\
\hline BIM consultant & 2 & BIM-ownership determination & 5 \\
\hline Space requirements & 1 & BIM consultant & 3 \\
\hline CAD rework cost & 1 & Contractual cost & 2 \\
\hline Contractual cost & 1 & Capital cost & 2 \\
\hline & & Risk of using a new technology & 1 \\
\hline
\end{tabular}

\section{Reference}

Arayici, Y., Coates, P., Koskela, L., Kagioglou, M., Usher, C., and O'reilly, K. (2011). Technology adoption in the BIM implementation for lean architectural practice. Automation in Construction, 20(2), 189-195.

Arrighetti, A., Bachmann, R., and Deakin, S. (1997). Contract law, social norms and inter-firm cooperation. Cambridge Journal of Economics, 21(2), 171-195.

Azhar, S. (2011). Building information modeling (BIM): Trends, benefits, risks, and challenges for the AEC industry. Leadership and Management in Engineering, 11(3), 241-252.

Azhar, S., Nadeem, A., Mok, J. Y., and Leung, B. H. (2008). Building Information Modeling (BIM): A new paradigm for visual interactive modeling and simulation for construction projects. In Proceedings of the First International Conference on Construction in Developing Countries, 435-446.

Becerik-Gerber, B. and Rice, S. (2010). The perceived value of building information modeling in the US building industry. Journal of Information Technology in Construction, 15(2), 185-201.

Berger, P. G. and Hann, R. N. (2007). Segment profitability and the proprietary and agency costs of disclosure. The Accounting Review, 82(4), 869-906.

Bryde, D., Broquetas, M., and Volm, J. M. (2013). The project benefits of building information modelling (BIM). International Journal of Project Management, 31(7), 971-980.

Camerer, C. (2003). Behavioral game theory: Experiments in strategic interaction. Princeton University Press.

Cao, D., Li, H., Wang, G., and Huang, T. (2016). Identifying and contextualising the motivations for BIM implementation in construction projects: An empirical study in China. International Journal of Project Management, In Press.

Ceric, A. (2012). Communication risk in construction projects: Application of principal-agent theory. Organization, Technology \& Management in Construction: An International Journal, 4(2), 522-533. 
Please cite this article as: "Zheng, L., Lu, W., Chen, K., Chau, K.W., and Niu, Y.H. (2017). Benefit sharing for BIM implementation: Tackling the moral hazard dilemma in inter-firm cooperation. International Journal of Project Management, 35(3), 393-405."

Chang, C. Y. (2014). An economic framework for analyzing the incentive problems in building information modeling systems. In Proceedings of Academy of Management Annual Meeting.

Chen, K., Lu, W., Peng, Y., Rowlinson, S., and Huang, G. Q. (2015). Bridging BIM and building: From a literature review to an integrated conceptual framework. International Journal of Project Management, 33(6), 1405-1416.

DPR Construction. (2010). A case study in work environment redesign. https://goo.gl/A4DTCz (Retrieved in Jan. 2016).

Duffy, J. and Ochs, J. (2009). Cooperative behavior and the frequency of social interaction. Games and Economic Behavior, 66(2), 785-812.

Eadie, R., Browne, M., Odeyinka, H., McKeown, C., and McNiff, S. (2013). BIM implementation throughout the UK construction project lifecycle: An analysis. Automation in Construction, 36, 145-151.

Eastman, C., Teicholz, P., Sacks, R., and Liston, K. (2011). BIM Handbook: A Guide to Building Information Modeling for Owners, Managers, Designers, Engineers, and Contractors. New Jersey: Wiley.

Eisenhardt, K. M. (1989). Agency theory: An assessment and review. Academy of Management Review, 14(1), 57-74.

Friedman, D. (1991). Evolutionary Games in Economics. Econometrica, 59(3), 637-666.

Giel, B. K. and Issa, R. R. (2011). Return on investment analysis of using building information modeling in construction. Journal of Computing in Civil Engineering, 27(5), 511-521.

Gintis, H. (2009). The bounds of reason: game theory and the unification of the behavioral sciences. Princeton University Press.

Goedert, J. D. and Meadati, P. (2008). Integrating construction process documentation into building information modeling. Journal of Construction Engineering and Management, 134(7), 509-516.

Groves, T. and Ledyard, J. (1977). Optimal allocation of public goods: A solution to the" free rider" problem. Journal of the Econometric Society, 783-809.

Hatch, M. J. and Cunliffe, A. L. (2013). Organization theory: modern, symbolic and postmodern perspectives. Oxford University Press.

Hess, C. and Ostrom, E. (2003). Ideas, artifacts, and facilities: information as a common-pool resource. Law and Contemporary Problems, 66(1/2), 111-145.

Hölmstrom, B. (1979). Moral hazard and observability. The Bell Journal of Economics, 74-91.

Holmstrom, B. and Milgrom, P. (1991). Multitask principal-agent analyses: Incentive contracts, asset ownership, and job design. Journal of Law, Economics, and Organization, 7, 2452.

Huber, D., Akinci, B., Oliver, A. A., Anil, E., Okorn, B. E., and Xiong, X. (2011). Methods for automatically modeling and representing as-built building information models. In Proceedings of the NSF CMMI Research Innovation Conference. 
Please cite this article as: "Zheng, L., Lu, W., Chen, K., Chau, K.W., and Niu, Y.H. (2017). Benefit sharing for BIM implementation: Tackling the moral hazard dilemma in inter-firm cooperation. International Journal of Project Management, 35(3), 393-405."

Kaner, I., Sacks, R., Kassian, W., and Quitt, T. (2008). Case studies of BIM adoption for precast concrete design by mid-sized structural engineering firms. Journal of Information Technology in Construction, 13, 303-323.

Kerosuo, H. and Paavola, S. (2016). Expansive uses of BIM and organizing BIM coordination. In Proceedings of 4th International Workshop When Social Science Meets Lean and BIM.

Love, P. E., Simpson, I., Hill, A., and Standing, C. (2013). From justification to evaluation: Building information modeling for asset owners. Automation in Construction, 35, 208216.

Lu, W., Fung, A., Peng, Y., Liang, C., and Rowlinson, S. (2014). Cost-benefit analysis of Building Information Modeling implementation in building projects through demystification of time-effort distribution curves. Building and Environment, 82, 317327.

Manu, E., Ankrah, N., Chinyio, E., and Proverbs, D. (2015). Trust influencing factors in main contractor and subcontractor relationships during projects. International Journal of Project Management, 33(7), 1495-1508.

MacLeamy, P. (2004). Collaboration, integrated information and the project lifecycle in building design, construction and operation. http://code bim.com/wpcontent/uploads/2013/06/CurtCollaboration.pdf(Retrieved in Aug. 2016).

McGraw Hill Construction. (2010). The Business Value of BIM in Europe. https://goo.gl/XB6xeO (Retrieved in Jan. 2016).

Merschbrock, C. and Rolfsen, C.N. (2016). BIM technology acceptance among reinforcement workers-the case of Oslo airport's terminal 2. Journal of Information Technology in Construction, 21, 1-12.

Obloj, T. and Zemsky, P. (2015). Value creation and value capture under moral hazard: Exploring the micro - foundations of buyer-supplier relationships. Strategic Management Journal, 36(8), 1146-1163.

Postrel, S. (2009). Multitasking teams with variable complementarity: Challenges for capability management. Academy of Management Review, 34(2), 273-296.

Redmond, A., Hore, A., Alshawi, M., and West, R. (2012). Exploring how information exchanges can be enhanced through Cloud BIM. Automation in Construction, 24, 175183.

Rico, D. F. (2006). A framework for measuring ROI of enterprise architecture. Journal of Organizational and End User Computing, 18(2), I.

Ross, S. A. (1973). The economic theory of agency: The principal's problem. The American Economic Review, 63(2), 134-139.

Schade, J., Olofsson, T., and Schreyer, M. (2011). Decision-making in a model-based design process. Construction Management and Economics, 29(4), 371-382.

Sebastian, R. (2011). Changing roles of the clients, architects and contractors through BIM. Engineering Construction and Architectural Management, 18(2), 176-187.

Simon, H.A. (1982). Models of bounded rationality: Empirically grounded economic reason (Vol. 3). MIT press. 
Please cite this article as: "Zheng, L., Lu, W., Chen, K., Chau, K.W., and Niu, Y.H. (2017). Benefit sharing for BIM implementation: Tackling the moral hazard dilemma in inter-firm cooperation. International Journal of Project Management, 35(3), 393-405.”

Son, H., Lee, S., and Kim, C. (2015). What drives the adoption of building information modeling in design organizations? An empirical investigation of the antecedents affecting architects' behavioral intentions. Automation in Construction, 49, 92-99.

Song, S., Yang, J., and Kim, N. (2012). Development of a BIM-based structural framework optimization and simulation system for building construction. Computers in Industry, 63(9), 895-912.

Staub-French, S., Forgues, D., Iordanova, I., Kassaian, A., Abdulaal, B., Samilski, M., Cavka, H. B., Nepal, M. (2011). Building information modelling (BIM): An investigation of "best practices" through case studies at regional, national and international levels. University of British Columbia.

Succar, B. (2010). The five components of BIM performance measurement. In Proceedings of CIB World Congress 2010.

Tang, P., Huber, D., Akinci, B., Lipman, R., and Lytle, A. (2010). Automatic reconstruction of as-built building information models from laser-scanned point clouds: A review of related techniques. Automation in Construction, 19(7), 829-843.

Taylor, J. E. and Bernstein, P. G. (2009). Paradigm trajectories of building information modeling practice in project networks. Journal of Management in Engineering, 25(2), 69-76.

Teicholz, E. (2001). Facility design and management handbook. McGraw Hill Professional.

Williamson, O. E. (1973). Markets and hierarchies. American Economics Review, 63(2), 316325.

Ward, S., and Chapman, C. (1994). Choosing contractor payment terms. International Journal of Project Management, 12(4), 216-221. 